\title{
Investigation and Research on Interpersonal Problem- solving Strategies for Children Aged 4 to 6 Years
}

\author{
Lina Zhang \\ Teachers' College Shenyang University \\ Shenyang, China
}

\author{
Xiaodong Pan \\ Teachers' College Shenyang University \\ Shenyang, China
}

\author{
Longhui $\mathrm{Wu}$ \\ Teachers' College Shenyang University \\ Shenyang, China
}

\begin{abstract}
-4-6 years old is an important period of children's social development, and interpersonal communication is an inevitable way of socialization of children. It is very important for children to use problem-solving strategies properly in interpersonal communication. This paper carried out an investigation and research of the present situation of interpersonal communication strategies among children in a private kindergarten of Guiyang by means of literature, questionnaire and observation. Based on the data, this paper conducts a comparative analysis of the age difference among children aged 4 to 6 years and the gender difference of same age in using the interpersonal problem-solving strategies, then analyzes reasons and puts forward some specific implementation recommendations.
\end{abstract}

Keywords-4-6 years old children; Interpersonal problems; Solving strategies; Problem situations

\section{INTRODUCTION}

\section{A. Interpersonal Relationship}

Interpersonal relationship is also known as interpersonal communication, which refers to the process of one individual's transferring some kind of information to other individuals by means of certain language, text or postures, expression, etc.[1] People are social animals and each individual has its own unique thoughts, background, attitude, personality, behavior pattern and value. However, interpersonal relationship has a great influence on each person's emotion, life and work, even greatly influences the organizational climate, organizational communication, organizational operation, organizational efficiency, and the relationship between the individuals and the organization [2].

The paper mainly studies the peer interaction between children, which is an "equal-free" relationship.

\section{B. Interpersonal Problem-solving Strategies for Children}

Strategies originally refer to the planning and command of large-scale operations, which are later summarized as a means or method to achieve some purpose [3]. Children's interpersonal problem-solving strategy is a solution to children when faced with some interpersonal communication problems. On the one hand, it is the comprehensive performance of children's social cognitive ability, and on the other hand, its development is also favorable to the improvement of children's social adaptability. Early researchers had analyzed and sorted out the context of children's interpersonal problems; found that the initiation of communication context, the maintenance of communication context, and the conflict resolution context cover three types of contexts in peer interactions in which children are most frequently involved in [4].

\section{INVESTIGATION AND RESEARCH ON INTERPERSONAL}

PROBLEM-SOLVING STRATEGIES FOR CHILDREN AGED 4 TO 6 YEARS

\section{A. Survey Object}

In this study, cluster sampling survey was conducted to randomly select a total of 200 children aged 4, 5, and 6 years from a private kindergarten in Guiyang City, Guizhou Province. All children and parents formed the survey object of this study.

\section{B. Survey Method}

(1) Questionnaire

This study made the questionnaire A Questionnaire on Interpersonal Problem-solving Strategies for the Pre-school Children by itself. 200 copies of questionnaires were issued to the teachers and parents from a kindergarten in Guiyang, of which 200 copies were recovered and 200 copies were effective. Statistical analysis was carried out with SPSS2.0.

\section{(2) Observation}

Through the observation method, the realistic behaviors of children in the daily communication contexts are recorded, and what strategies the children will use in these contexts will be understood. This study and observation will divide 4 years old, 5 years old and 6 years old into one group respectively. Each group has 24 children with 12 boys and 12 girls. 


\section{Contents of the Survey}

\section{1) Contents of the Questionnaire}

It is a series of questionnaire questions about how children can do and influence the interpersonal problem-solving strategies of children in the three contexts of the initiation of communication, maintenance of communication and conflict resolution.

\section{2) Contents of the observation}

(1) Observation I: In the regional corner activity, the teacher distributed 6 Peppa Pig to each group of children, staying at the side without any interference, and allowing the children to play freely. The observers made the recording.

(2) Observation II: In the social class specially arranged by the teacher, play some pictures and animations of the small contexts of the communication problems and ask for questions to the children. The observers quickly recorded the children's answers.

\section{Survey Results}

\section{1) Results of the Questionnaire}

Result I: The following table was the data of the strategies used by children in the initiation of communication context through questionnaire: A. Language invitation. e.g. "Do you come and play games with me?" B. Sharing. e.g. Take out your own toys and play with other children together $\mathrm{C}$. Praising. e.g. "You are wearing a nice dress today. Can you play with me?" D. Just pull the children to play games together. E. Feel shy to invite, firstly play by itself, and then wait for other children's joining.

TABLE I DATA IN THE CONTEXT OF CHILDREN'S INITIATION OF COMMUNICATION

\begin{tabular}{|c|c|c|c|c|c|c|}
\hline $\begin{array}{c}\text { Age } \\
\text { Stcategy } \\
\text { A }\end{array}$ & 4-year-old girl & 4-year-old boy & 5-year-old girl & 5-year-old boy & 6-year-old girl & 6-year-old boy \\
\hline B & $18.75 \%$ & $21.05 \%$ & $25.00 \%$ & $36.36 \%$ & $28.57 \%$ & $42.50 \%$ \\
\hline C & $0.00 \%$ & $2.63 \%$ & $12.50 \%$ & $6.06 \%$ & $14.29 \%$ & $5.00 \%$ \\
\hline D & $3.13 \%$ & $7.90 \%$ & $9.38 \%$ & $6.06 \%$ & $5.71 \%$ & $5.00 \%$ \\
\hline E & $32.00 \%$ & $21.05 \%$ & $6.25 \%$ & $12.12 \%$ & $2.86 \%$ & $22.5 \%$ \\
\hline Total & $100 \%$ & $100 \%$ & $100 \%$ & $100 \%$ & $100 \%$ & $100 \%$ \\
\hline
\end{tabular}

As can be seen from Table 1, in the initiation of communication context, the strategies used by children are more appropriate and richer with the increase of age, among which 4 to 5 year old has the largest span, and the frequency of using sharing and praising strategies is greatly increased. Besides, there are differences in the strategies used by the children of the same age but of different gender.

Results II: (1) Figure 1 is the parenting style of children aged 4 to 6 years. Red is the permissive parenting, accounting for $71.36 \%$; Green is the indulgent parenting (neglectful parenting), accounting for $48.24 \%$; Purple is the democratic parenting (authoritative parenting), accounting for $42.21 \%$; Blue is the authoritarian parenting, accounting for $39.19 \%$.

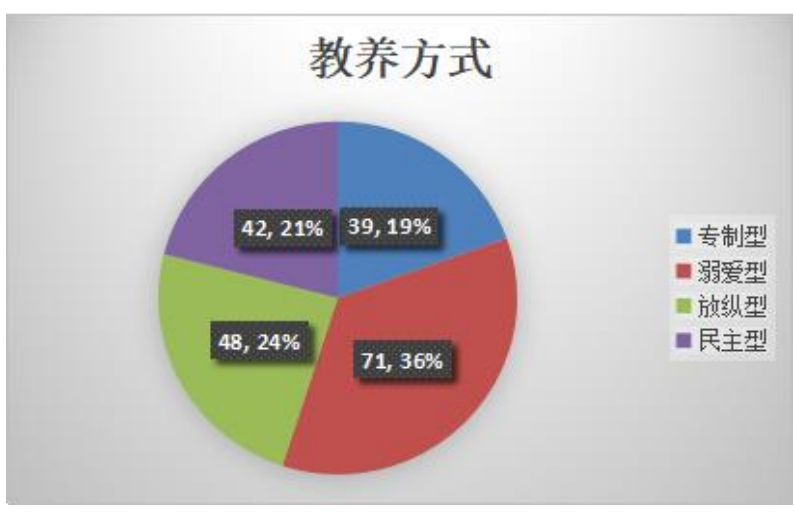

Fig. 1 Data about the cultivation style of the family to children

(2) Figure 2 is the type of the favorite mobile games for the children aged 4 to 6 years. Blue is an puzzle leisure type, accounting for 44\%; Red is the action fighting type, accounting for 28\%; Green is a racing adventure type, accounting for $16 \%$; Purple is the chess sports type, accounting for $12 \%$.

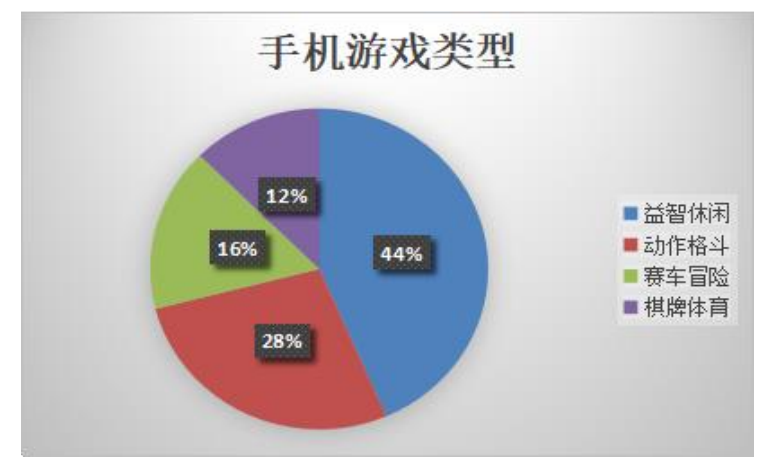

Fig. 2 Data about the children's favorite games

(3) Figure 3 is the type of the favorite animations for the children aged 4 to 6 years. Red is the hero type, accounting for $42 \%$; Blue is the humorous type, accounting for $32 \%$; Green is the didactic type, accounting for $26 \%$.

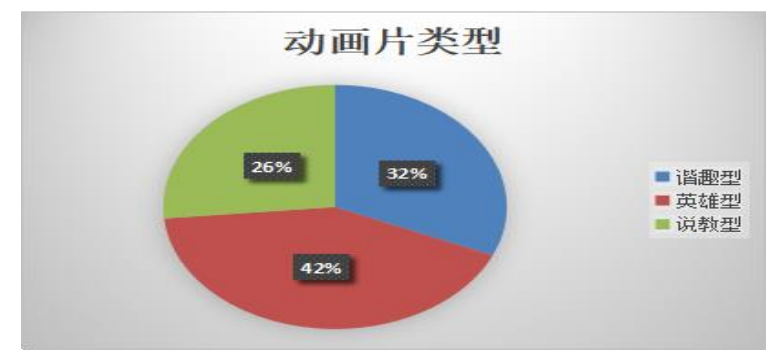

Fig. 3 Data about the children's favorite animations 
Communication and consultation e.g. "I'll play for a while. You play for a while." C. Denouncement and dispute. e.g. "You go away. This is the thing I've got first." D. Force, fight, and body conflict E. seek for help. Seek help to the teacher.

\section{2) Results of the Observation}

Observation I: The following table is the data about the strategies used by children in conflict resolution context when they are in the regional corner activity: A. Concession. The children actively let other children play their toys. B.

TABLE II DATA IN THE CONTEXT OF CONFLICT RESOLUTION FOR CHILDREN

\begin{tabular}{|c|c|c|c|c|c|c|}
\hline $\begin{array}{c}\text { Age } \\
\text { Strategy }\end{array}$ & 4-year-old girl & $\begin{array}{c}\text { 4-year-old } \\
\text { boy }\end{array}$ & $\begin{array}{c}\text { 5-year-old } \\
\text { girl }\end{array}$ & $\begin{array}{c}5 \text {-year-old } \\
\text { boy }\end{array}$ & 6-year-old girl & $\begin{array}{l}\text { 6-year-old } \\
\text { boy }\end{array}$ \\
\hline $\mathrm{A}$ & 2 & 1 & 3 & 3 & 4 & 3 \\
\hline $\mathrm{B}$ & 3 & 2 & 4 & 3 & 5 & 5 \\
\hline $\mathrm{C}$ & 2 & 3 & 1 & 2 & 0 & 1 \\
\hline $\mathrm{D}$ & 1 & 4 & 1 & 2 & 1 & 2 \\
\hline $\mathrm{E}$ & 4 & 2 & 3 & 2 & 2 & 1 \\
\hline Total & 12 & 12 & 12 & 12 & 12 & 12 \\
\hline
\end{tabular}

Observing the data in table 2 showed that children's use of positive strategies has gradually increased with the increase of age in the context of conflict resolution. At the same time, there are differences in the strategies used by the children of the same age but of different gender. In general, girls use more communication and consultation strategy and the help strategy than boys, and boys use more denouncement strategy and force strategy than girls.
Observation II: The following table is the data used by the children in the maintenance contexts when the teacher was having social classes (Note: the data in the form is the total number of uses in all three maintenance contexts): A Communication and consultation B. Provision of benefits $\mathrm{C}$ Waiting D Giving up E Others.

TABLE III DATA IN THE CONTEXT OF MAINTENANCE OF COMMUNICATION

\begin{tabular}{|c|c|c|c|c|c|c|}
\hline $\begin{array}{c}\text { Age } \\
\text { Strategy }\end{array}$ & 4-year-old girl & $\begin{array}{c}\text { 4-year-old } \\
\text { boy }\end{array}$ & $\begin{array}{c}\text { 5-year-old } \\
\text { girl }\end{array}$ & $\begin{array}{c}\text { 5-year-old } \\
\text { boy }\end{array}$ & $\begin{array}{c}\text { 6-year-old girl } \\
\text { 6-year-old } \\
\text { boy }\end{array}$ \\
\hline $\mathrm{A}$ & $44.44 \%$ & $52.78 \%$ & $50.00 \%$ & $52.78 \%$ & $55.56 \%$ & $55.56 \%$ \\
\hline $\mathrm{B}$ & $2.78 \%$ & $5.56 \%$ & $11.11 \%$ & $5.56 \%$ & $11.11 \%$ & $8.33 \%$ \\
\hline $\mathrm{C}$ & $16.67 \%$ & $11.11 \%$ & $5.56 \%$ & $11.11 \%$ & $8.33 \%$ & $8.33 \%$ \\
\hline $\mathrm{D}$ & $19.44 \%$ & $13.89 \%$ & $11.11 \%$ & $13.89 \%$ & $5.56 \%$ & $11.11 \%$ \\
\hline $\mathrm{E}$ & $16.67 \%$ & $16.67 \%$ & $22.22 \%$ & $19.44 \%$ & $19.44 \%$ & $16.67 \%$ \\
\hline Total & $100 \%$ & $100 \%$ & $100 \%$ & $100 \%$ & $100 \%$ & $100 \%$ \\
\hline
\end{tabular}

Observing the data in table 3 showed that in the context of maintenance of communication and with the increase of age, there aren't great differences in children's use of the strategies, while there are obvious decreases in the use of giving up strategy. At the same time, there are slight differences in the strategies used by the children of the same age but of different gender, but the differences are not great.

\section{CAUSES OF THE DIFFERENCE IN THE CHILDREN'S INTERPERSONAL PROBLEM-SOLVING STRATEGIES}

\section{A. Factor of Children}

\section{1) Age Difference}

There are differences in children's cognitive level in different age groups. In the initiation of communication context, the maintenance of communication context, and the conflict resolution context, the higher the age of children, the higher the level of cognitive development [4]; Due to the strong self-centered consciousness and the lack of communication experience for the 4-year-old children, they lack predictable capacity for behavioral outcomes, so they are more inclined to the force strategy and help strategy. The 5year-old children have a certain interpersonal communication experience, and know that the use of sharing and praising strategy will achieve the recognition of the companion, so as to achieve the successful initiation.

\section{2) Gender Difference}

In the communication context, girls use the strategy of language invitation and praising more frequently than boys, and the times for the boys to use the sharing strategy is higher than that of the girls. In the conflict resolution context, boys have more active character. They are more likely to be impulsive, and would use more negative strategies. Girls are more introverted, shy, and more self-control than boys. In the maintenance of communication context, there are no significant differences in the use of strategies for the children of the same age but of different gender.

\section{B. Factor of Family}

According to the questionnaire, if parents are too permissive at the children, it can lead to the self-centered consciousness of the children and they are more prone to solve problems by force. The long-term rough behaviors of parents can not only cause children psychological problems, but also allow them to imitate. Other partners will gradually isolate them for being hurt. 


\section{Factor of Teachers}

In the study of the questionnaire, it was found that the teacher's own language attitude had a subtle influence on children. For example, when the teacher tells the stories lively and emotionally, the children will make the same crying, laughing, sad, happy and even excited to jump to react to the story according to the contents narrated by the teacher. Otherwise, the children are not willing to talk or express themselves.

\section{Factor of Network Media}

The study found that only a small number of families prohibited children from playing their mobile phones or allowed them to watch television for only twenty minutes. Most children spent more than half an hour or even an hour at home in watching TV. If a child is obsessed with the world of electronic network and immersed in mobile television, it can cause him to be unwilling to communicate with other people. He will seriously lack of interpersonal skills and interpersonal problem-solving strategies and can not be integrated into the real world.

\section{RECOMMENDATIONS FOR IMPROVING THE INTERPERSONAL PROBLEM-SOLVING STRATEGIES FOR CHILDREN AgED 4 TO 6 YEARS}

\section{A. Improve the Language Ability of Children and Strengthen the Training of Interpersonal Problem-solving Strategies}

Specific methods to improve the language ability of children: Firstly, the kindergarten sets up the book corner, the exhibition area, the small broadcaster, and makes full use of the environmental design. Secondly, teachers organize the children to engage in conversations, such as morning sitting activities to share their experience together. Finally, parents should establish an equal relationship with their children when talking, such as squatting to communicate with them and paying attention to speaking Mandarin, being civilized, speaking fluently and so on[7] .

Early intervention studies have confirmed that the training of interpersonal problem-solving strategies can increase the positive behavior of children and improve interpersonal relationships among children. The kindergarten should offer courses of interpersonal problem-solving strategies. Both teachers and adults should give more patience to children in daily life. When children encounter interpersonal problems, observe and guide the children to solve the problems in a positive and friendly way [5].

\section{B. Help children overcome the self-centered consciousness, and learn to think in a manner of exchanging position}

Peer interaction requires an equal and harmonious relationship, and children must be made aware that everyone has the same rights when playing with their friends, and they should be friendly and considerate for others [13]. Specific methods: Firstly, set the boundaries of behavior at home for children. Secondly, make use of stories, children's songs and so on to let the children learn humility and sharing, and organize the sharing day, etc. Finally, make use of musical drama, performance stories and so on to make the most naughty children perform the role of bullying.

\section{Help Children Learn to Adjust their Emotions and Strengthen Children's Correct Interaction Behavior}

Parents and teachers should actively guide the children to adjust and control their emotion, provide children with the opportunity to vent, and teach them the behavioral norm of interpersonal communication. Help children adapt to an unfamiliar environment in a timely manner, learn to express their own ideas, and control the unreasonable behavior [6]. Specific method: Firstly, divert the attention. When a child's emotion can't be controlled, let him calm down and then consult with him. Secondly, actively guide the child to think in a manner of exchanging position, and children aged 5 and 6 years have been able to understand the behavior of others. Finally, create an environment. Teachers should create a loving psychological environment for children and should be neat, beautiful and scientific in material environment.

\section{Improve Children's Ability to Predict Behavioral Outcomes and the Levels of Self-control}

The children aged 4 to 6 years have limited cognitive development level. They are not aware that the sharing, praising, the provision of benefits and other negative prosocial behaviors will make other children happy and glad and the passive strategies such as denouncement and force could easily make other children feel sad and hurt[7]. Teachers and parents should guide the children to understand the consequences of the use of positive strategies and negative strategies through the specific interpersonal problem contexts in life and patient explanations, thereby improving children's self-control level and enabling them to analyze the contexts and take effective and appropriate solutions. Children's ability to predict the behavioral outcomes can also be improved through specialized courses, animations, and stories.

\section{CONCLUSION}

(1) With the increase of the age of children, the interpersonal problem-solving strategies are more active and rich. Especially, there are obvious differences in using the strategies for the children aged 4 and 5 years.

(2) There are differences in using the strategies for the children of the same age but different gender. Girls are more likely to use the language strategies such as praise, communication, and consultation, as well as the help strategy. In solving the conflicts, boys are more likely to use strategies such as denouncement and force. The gender and age difference in the context of maintaining communication is not very great, but the abandonment strategy gradually decreases.

(3) The teachers and parents should be patient in the specific interpersonal problem context to guide the children to adopt the pro-social positive strategies, and the kindergarten should offer the course of interpersonal problem strategy training so as to promote the improvement of children's interpersonal problem-solving strategies through the cooperation between family and kindergarten. 


\section{REFERENCES}

[1] Zong Aidong, Shi Lijuan. Study on the problem-solving strategies for children aged 3 to 5 years in the context of interpersonal conflict stories [J]. Shanghai Research on Education, 2010(26): 84-85.

[2] Liu Chao. The analysis of the difference in interpersonal problemsolving strategies for different socially-withdrawn children [D];
[Den Literature Education, 2017.

[3] Zhao Jinxia, Wang Meifang. Development of interpersonal problemsolving strategies for children aged 4 to 6 years and its educational enlightenment [J]. Studies in Preschool Education, 2006(12): 9-11.

[4] Zhao Jinxia, Wang Meifang. Development of interpersonal cognitive problem-solving and preschooler's anxiety symptoms and peer interaction [J]; Studies in Preschool Education, 2011(2): 37-40.

[5] Zhou Lihua, Cao Zhongping, Su Linyan. Research on the Preschoolers' Peer Interaction Strategy System in the Play Context [J]; Studies in Preschool Education, 2012 (4): 36-40.

[6] Chen X. Culture, types of social withdrawal, and children's beliefs from an integrative perspective $[\mathrm{J}]$, British Journal of Developmental Psychology, 2015, 33 (2): 174-176.

[7] Feng.X.Harkness,S,Super,C.M.Jia,R.Shyness and adaptation to school in a Chinese community [J]. Infant and Child Development,2014,23(6),662-671. 